https://helda.helsinki.fi

\title{
Supporting students' transition to higher education
}

\section{Perander, Katarina}

2021-05-04

Perander , K , Londen , M \& Holm , G 2021 , ' Supporting students' transition to higher education ' , Journal of Applied Research in Higher Education , vol. 13 , no. 2 , pp. 622-632 . https://doi.org/10.1108/

http://hdl.handle.net/10138/332891

https://doi.org/10.1108/JARHE-01-2020-0005

unspecified

acceptedVersion

Downloaded from Helda, University of Helsinki institutional repository.

This is an electronic reprint of the original article.

This reprint may differ from the original in pagination and typographic detail.

Please cite the original version. 


\section{Supporting students' transition to higher education}

\section{Abstract}

Purpose

The purpose of this study was to investigate how a workshop can enhance first-year university students' understanding of their study strategies and self-regulated learning.

\section{Methodology}

A qualitative content analysis was done of 190 reflective journals written by first-year university students.

\section{Findings}

The main findings confirmed that starting studies in higher education is challenging for many students. New insights were provided on how these challenges can be addressed, especially regarding self-regulated learning. Students perceived that they gained several insights from the workshop that they believed could benefit their studying and thereby enhance motivation.

\section{Practical implications}

This study showed that even small measures promote both good study habits and specifically selfregulated learning skills. Interventions like the workshop described in this study ease first-year students' transition to the university and foster successful studies for all students.

\section{Originality/value}

This study contributes to research on supporting students' transition to higher education by investigating how students perceive early study skill interventions. It adds to a holistic perspective of students' challenges and coping strategies during their first semester in higher education.

Keywords: intervention, higher education, first-year students, self-regulated learning

Article classification: Research paper

\section{Introduction}

Starting higher education (HE) studies often requires substantial changes by students. Not only do they need to improve their study skills, but students also need to re-evaluate their study habits more generally (Leese, 2010). Moreover, a well-recognized challenge in Finland is that only $65 \%$ of students graduated within the expected timeframe in 2018 (OSF, 2020). However, the number of students graduating within the expected timeframe has increased by $12 \%$ in five years. This can partly be explained by stricter university rules and more strenuous terms for students' eligibility to receive study allowances. Universities worldwide have paid increasing attention to first-year students, since the first year in HE has profound effects on study progress and graduation (Hailikari et al., 2019). However, promoting only study skills does not necessarily lead to the changes intended (Jairam, 2019). Rather, research has shown that especially motivation and self-regulated learning affect academic transition to HE which in turn affects academic progress and retention (van Rooij et al., 2018). 
The aim of this study was to provide an example of an easily viable intervention: a compulsory sixhour workshop in study strategies for first-year students, at the aim of which was to support students' transition to HE by strongly relying on the knowledge about first-year students' challenges gained from previous research. The purpose of the workshops was to promote good self-regulated learning (SRL) and stress management skills. The participating students $(\mathrm{N}=190)$ reflected on their study habits and SRL skills in reflective journals. Reflective journaling has been used among first-year students as a tool to promote independent learning and retention (Brooman and Darwent, 2012a; Brooman and Darwent, 2012b). The benefits of reflective journals for independent learning have been demonstrated especially among academically average students (Cicero 2006; Kim, 2013). This study contributes to existing research on first-year experience by exploring how students perceive the intervention and how they make their study habits meaningful by analyzing their studying. This is important since their perspective affects the factors they find enhance and impede their studies. Thereby, the intervention is evaluated, and the results can be used in future interventions.

\section{Studying in higher education}

Previous research shows that successful studying in HE requires motivation, good study habits and self-regulated learning (SRL) skills (Cassidy, 2011; Haarala-Muhonen et al., 2017; Richardson et al., 2012). SRL means that students are active participants in their learning process and can reflect on their learning metacognitively, motivate themselves and also act in line with their intentions (Pintrich, 2004; Zimmerman, 1986). Furthermore, students are assumed to have a goal, criterion or standard against which they evaluate their own learning process. SRL mediates the effect of personal and contextual characteristics on actual performance (Pintrich, 2004). Moreover, self-regulated learners monitor their behavior through the awareness of their strengths and limitations in specific learning settings (Zimmerman, 2002). Thus, SRL implies that students can choose appropriate learning strategies for different tasks.

Studying in HE requires more independent learning and SRL skills than earlier levels of education, which can be challenging for new students (Foerst et al., 2017). Independent learning also requires self-discipline and good time-management skills. When students have enough self-discipline, they are able to motivate themselves and manage their time. This is especially important in distance learning. Students who adopt early good SRL skills also graduate faster (Hailikari et al., 2019). Obstacles and challenges are also more easily overcome by students who have good SRL skills because they focus more on enhancing than on impeding factors (Hailikari and Parpala, 2014). However, students' SRL is affected by several factors. According to Dweck and Master (2008) students' self-theories affect SRL via their effort beliefs. Students who believe that they can improve their achievement and ability via effort (i.e., growth mindset) use more SRL strategies and are more driven by intrinsic motivation. Moreover, they invest more effort in academic tasks and aim for improvement (Yan et al., 2014). Thus, they use fewer self-handicapping activities like procrastination (Dweck and Master, 2008). By contrast, students who believe ability is innate (i.e., fixed mindset) use fewer SRL strategies and make less effort. Hence, interventions that target growth mindset have affected academic success positively (Broda et al., 2018).

Previous research has also shown that good time-management skills and effort is related to study success throughout university studies (Asikainen et al., 2014). However, procrastination is common among university students and impedes academic progress (Kim and Seo, 2015). Procrastination is defined as the voluntary delay of intended and necessary and/or [personally] important activity, despite expecting potential consequences of the delay (Klingsieck, 2013, 16). The academic freedom 
within universities can have the effect of increasing procrastination, especially if students lack sufficient SRL skills (Lindblom-Ylänne et al., 2015). In contrast to Steel (2007) who claims that procrastination is a failure to self-regulate, Klassen et al. (2008) highlight the importance of selfefficacy to self-regulate in order to understand procrastination. However, Katz et al. (2014) argue that intrinsic motivation, characterized by engagement and interest, mediates the effect of selfefficacy on procrastination. They claim that high self-efficacy beliefs are not enough to reduce procrastination if students lack motivation. Nonetheless, students with high intrinsic motivation but low self-efficacy beliefs also procrastinate more than self-efficacious students (Katz et al., 2014). They suggest that interventions that target students' procrastination should focus on both students' self-efficacy beliefs and on intrinsic motivation. Moreover, research shows a strong correlation between freshman transition interventions and SRL, academic retention and graduation (CambridgeWilliams et al., 2013). Therefore, procrastination, impulsiveness and self-discipline should be targeted in interventions (Steel and Klingsieck, 2016; van Eerde and Klingsieck, 2018) First-year seminars also affect attitudes toward university studies in general (Al-Sheeb et al., 2018).

\section{Workshop, context and participants}

The intervention in this study was a compulsory workshop on study strategies $(2 \times 3 \mathrm{~h}$ in-class or online) during first-year university students' first semester at a public university in Finland. The workshop was held by three teachers (a study psychologist, a lecturer in university pedagogy, and a social psychologist) who were not teachers in the students' study programs. The workshop topics included academic skills (reading and writing academic texts and notetaking), time-management, learning strategies, stress management and motivation. These topics were chosen because they have been shown to be crucial for studying in HE (e.g., Asikainen et al., 2014; Hailikari et al., 2019; Lindblom-Ylänne et al., 2015). Therefore, the workshop comprehensively covered factors significant for students' transition into HE. Another aim of the workshop was to foster a growth mindset among students in order to enhance their motivation and use of SRL strategies. Alongside in-class meetings, at which much focus was on reflective and informal discussions and support, students were provided with web-based instructional videos on, e.g., effective studying, stress-management, academic skills and procrastination. The in-class meetings were held two weeks apart. During these two weeks the students were required to track their use of time hour-by-hour for a whole week. Alternatively, students could complete the course online through self-study. The assignments were the same. Before the workshop all students submitted a pre-assignment in which they described their study challenges and expectations for the workshop.

The material for this study was collected from five workshops that were held between 2014 and 2017, three of them in-class and two online. All participating students were in the social sciences department. Most of the students (71\%) were $18-21$ years old, $21 \%$ were $22-25$, 3\% were $26-30$, and $5 \%$ were older than 30 years old. After the workshop the students wrote reflective journals in which they were asked to reflect on their study habits and strategies related to time-management, learning strategies and motivation for studying. They submitted the journal at the beginning of the following semester in order to have enough time to try new study strategies after the workshop. The workshop was graded with pass, fail, or should be revised. The fail grade was given when students did not return the assignment on time. They were required to revise when the journal only echoed the workshop topics and lacked personal reflections. Before the workshop, 190 students consented for their journals to be used for research. They were 1-8 pages long, comprising a total of 643 pages. The quotes were translated into English and details that could reveal the participants' identity were 
deleted or changed in order to ensure confidentiality. The study followed the ethical guidelines for research provided by the Finnish Advisory Board on Research Integrity (2012).

\section{Analysis}

The analysis of the reflective journals was conducted through qualitative inductive content analysis (Cho and Lee, 2014; Finfgeld-Connett, 2014). The advantage of this approach is to gain information from the participants' own perspective without imposing categories constructed beforehand. The reflective journals were reviewed repeatedly and the analyses iterated before the final categories were determined in order to discover all the key categories. Data segments describing similarities in challenges perceived by students and their perceptions of the insights provided by the workshop were identified, coded and grouped for analysis. The coding process relied on also identifying latent content meaning in the students' texts rather than relying solely on the visible content (Graneheim et al., 2017). The analysis was conducted by the first author. However, overlapping categories and interpretations were discussed and revised with the other authors to reach consensus and to reflect on the findings in light of existing research on the topic.

The following categories emerged in the analysis: workshop experiences (positive or negative, when mentioned), reflections on time-tracking assignment, challenges in $\mathrm{HE}$, metacognitive awareness, motivation, and integrated insights from the workshops. When students explicitly praised the workshop, it was coded as the sub-category positive workshop experience. Likewise, the subcategory negative workshop experiences was identified in journals when students clearly expressed discontent with the workshop or part of it. The reflections on time-tracking assignment code was identified when students described new personal insights the assignment revealed. All obstacles related to studying that students mentioned were coded as challenges in HE. Sub-categories identified within challenges in HE were related to SRL (especially time-management), academic emotions and practical issues. Students' reflections on how they learn and what strategies work for them were interpreted as metacognitive awareness. Both high and low motivation, as well as factors increasing or decreasing motivation, were coded as motivation. Finally, the integrated insights code was identified when students clearly discussed knowledge gained during workshops and how they could integrate it in their own studying.

\section{Findings}

The proportions of the occurrence of the categories in the reflective journals is shown in Table 1. Although, no direct workshop feedback was asked from the students, nearly half of the students gave feedback in their reflective journals. 


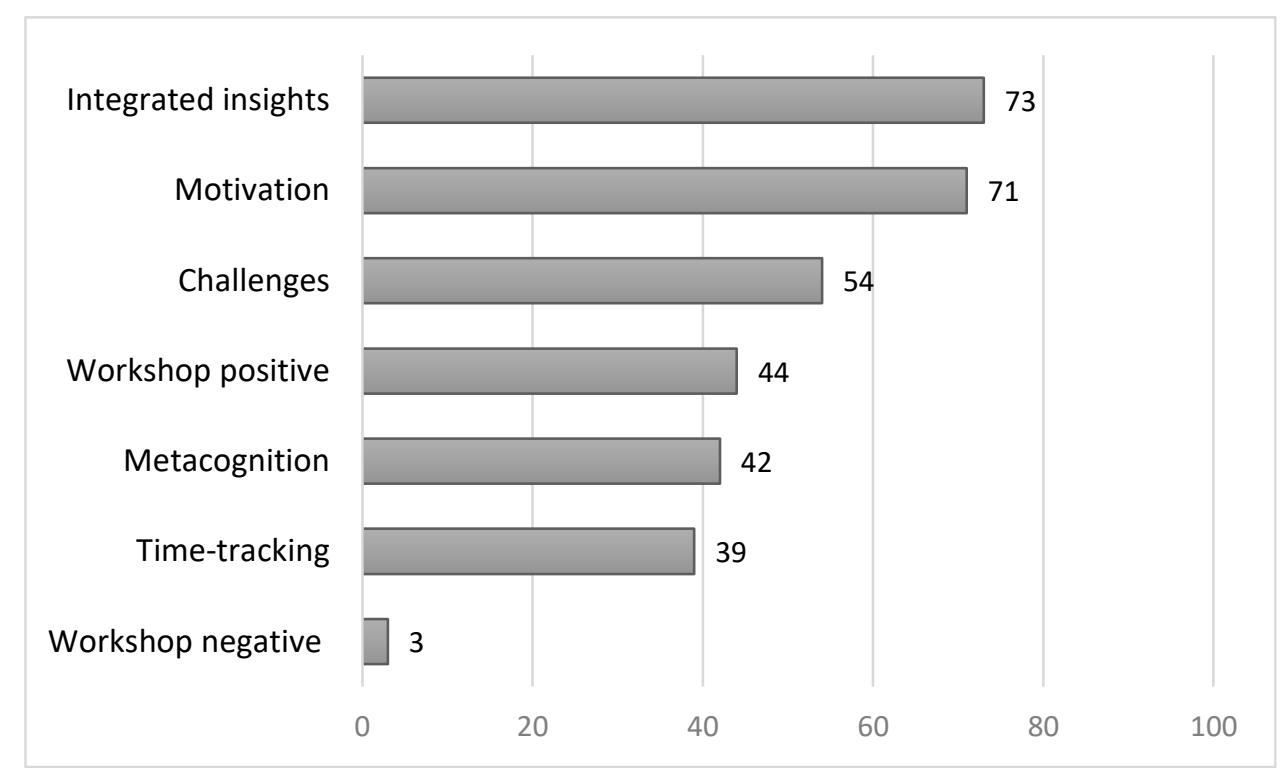

Table 1. Proportion of categories (\%) mentioned in all reflective journals.

Forty-four percent of the students wrote positive comments about the workshop compared to only three percent negative comments. The negative comments concerned the content being too familiar, the timing of the workshop too late (in the middle of the first semester) or that the workshop increased their stress levels by making them aware of what they did insufficiently. However, all these students described good SRL skills. Therefore, they were probably not among students benefiting most from similar interventions (e.g., Dörrenbacher and Perels, 2016). The reflective journals were not anonymous, which might have made the students more reluctant to criticize the workshop. However, the feedback was offered voluntarily by the students. Moreover, the reflective journals were written and assessed in a non-threatening environment and students received a pass simply by doing the reflections on time. Students who reported positive experiences mentioned topics such as time-management, study techniques (reading, taking notes, preparing for lectures and exams) as well as the relief they felt in being able to share their feelings of insecurity with other students during first semester in $\mathrm{HE}$.

This course has opened my eyes for my own shortcomings but also for my advantages, although they are few. I consider this course essential for most of the new students who might feel low-spirited about their studies. This course was an excellent chance to self-reflect and to see that others hesitate too. A completely new connection emerged between us.

Merely being able to name the disadvantageous behavior, e.g., procrastination, was a relief for the students by providing them with a shared language that made it easier to identify their dysfunctional study strategies. Overall, students were optimistic about their forthcoming studying at university. The workshop was perceived as giving them confidence and tools with which to tackle future study challenges. However, students described how mere knowledge of planning and time-management was not enough if the knowledge did not result in action. Acknowledging this dissonance between knowledge and action has been shown to be important in previous research (Foerst et al., 2017). The time-tracking assignment was a way of revealing how much time students used for studying 
compared to how much they thought they used. Thirty-nine percent of the students described the insights they acquired from the assignment. Students were baffled by how little time they actually spent studying during that week and how much time they spent doing nothing at all or pretending to study while being distracted by something else. Using their time efficiently before, between or after lectures was a challenge for students. The students were very honest about their dysfunctional habits and they admitted freely that they spent an excessive amount of time on (social) media when they should have been studying to keep up with their deadlines. They were also judgmental of themselves in their reflections as the excerpt below shows.

When I look at my time-tracking assignment, I can see straight away that independent study (I chose to call it homework) takes very little of my time. Most of my time goes to Netflix, other things or "homework". The last-mentioned means that I try to do something that makes sense, but I fail.

Moreover, students explained that they thought they could control their time, but by the end of the day they realized that they had not accomplished anything worthwhile. Yet, there were also students who were conscientious and self-disciplined. They described that the time-tracking assignment made them realize that they already had studied a full day and thereby could allow themselves to take some time off. In this sense, similar workshops also benefit students with good SRL skills by helping them balance their studies with their leisure time. Students explained that they were able to enjoy their leisure time more if they felt that they had earned it by working hard.

\section{Study challenges, metacognition and motivation}

More than half of the students (54\%) described challenges during their first semester in HE. Students who had achieved well in high school explained how they were shocked when they performed poorly or failed exams. They were not prepared for the adjustment required at university and felt they needed to re-evaluate their study strategies completely. This is in line with previous research (Leese, 2010). Procrastination and difficulty getting started was acknowledged by the students as challenging (see also e.g., Kim and Seo, 2015). However, the reasons students gave for procrastination varied. They were inability to assess accurately how much time they needed for exam preparation, difficulties in prioritizing between assignments, motivational issues, high performance pressure, unclear expectations, lack of useful study strategies or simply waiting too close to the deadline to get things done.

\footnotetext{
It was challenging to learn everything from the beginning. Where do you borrow textbooks, how do you read the textbooks so you learn? I managed to get the books but then they lay on the table unopened until it was time for my exam and I realized that I "should" have begun earlier. To try to grasp the material at that point was impossible. You know the expectations are different but, you don't know what is expected and what you should do to make it.
}

A lack of control was perceived to cause increased procrastination. When students felt they did not know how to begin or how to complete an assignment, they were inclined to postpone it. However, the temporary relief procrastination offered was overshadowed by the negative academic emotions the students experienced. 
I was constantly aware of all the things I needed to get done and they haunted me persistently. I did everything at the last minute. It was scary to realize that I actually didn't get anything done because I was neither focused on leisure time nor on studying. The only thing I did was creating more agony. The less control I perceived that I had, the more I procrastinated.

Practical challenges, such as deciding which courses to enroll in, how to get hold of course literature and how to use web platforms, can feel overwhelming for new students and aggravate the transition to HE (Trautwein and Bosse, 2017). These challenges were dealt with during the workshop and by the end of the first semester students were accustomed to how the university works. However, challenges with overwhelming emotions were described by the students in their reflective journals. Academic emotions and studying are complexly intertwined (Author 1 et al., 2020), as this student describes.

My studying and my leisure time were overshadowed by a constant worry about what I should do the next day, and how much studying I still had to torture myself with the ongoing week. And if I didn't study, I was terribly anxious and could wake up in the middle of the night not being able to fall asleep again due to feelings of guilt for not studying.

The students were aware of the vicious circle of procrastination and increased stress, and how it affected their self-confidence. However, they explained that as their metacognitive awareness increased, they became more confident and found it easier to organize their studying. Previous studies have shown that metacognitive awareness needs to be taught to new students in HE (Ruohoniemi and Lindblom-Ylänne, 2009). Students in this study frequently described (42\%) learning strategies they perceived to be useful. For example, preparing for lectures in advance helped them understand the lecture and reduced the amount of studying at the end of the course. Also discussing the topics and therefore having to verbalize the course content was perceived to enhance learning. Nevertheless, motivational issues were discussed in $71 \%$ of the reflective journals, which underlines the importance of interventions that increase student motivation (e.g., Katz et al., 2014). However, the interaction between motivation and planning seemed to be bidirectional.

There are times when I feel a total lack of motivation to do anything, mostly due to bad planning that leaves me with half the book left to read just before the exam. The better I plan and feel that I reach what I intended, the higher my motivation is.

Students described a lack of motivation in relation to uninteresting courses, but decreased motivation was also explained as related to poor planning and accumulating unfinished study assignments. Genuine interest in the subject, the reward of getting things done and career prospects after graduation were factors that students described as increasing their motivation. 
Integrated insights

Nearly three-quarters (73\%) of the students described new insights from the workshop (lectures, discussions, web-material or assignments) that they found useful and planned to apply or had already applied in their studying. Students explained how improved planning and time-management skills increased their control beliefs as well as their confidence in studying.

By paying attention to my study technique and time-management, I have really learned many useful things. By planning and realizing that I have to invest in what's important, it feels like I've got much more time! Now it feels like I can manage my studying and I understand how it works and how I'm supposed to study.

By careful and realistic planning students perceived that they could reduce stress, which they explained affected their overall wellbeing. Students also described how they had improved their study skills. For example, they started to pay attention to the learning outcomes of the course and use them as guidance in finding suitable study strategies. They also found new ways to tackle the course literature that was previously experienced as overwhelming. Also, specific skills on notetaking or exam preparations were perceived as being useful.

I will try to invest more in a deep approach to learning by checking out the topic of the next lecture in advance, do some research in the subject and write questions about it. Trying to understand, rather than memorize without understanding. Before exams I will try to allot enough time for repetition. Most importantly, I will curb my perfectionism. I have to allow myself to fail sometimes because that is also how you learn.

By discussing with other students during the workshop and by reflecting on their own, they became aware of their sometimes dysfunctional study strategies. To summarize, although the workshop was short, most of the students acquired both theoretical and practical advice to integrate into their own studying.

\section{Discussion}

The aim of this study was to investigate how workshops on study strategies can enhance first-year university students' understanding of their study strategies and SRL skills. The main results show that most of the students gained several insights from the workshop that they had applied or planned to apply in their studying. Students in this study described a complex set of challenges that were intertwined: study skills, emotions, motivation and SRL skills. More stern expectations of good time-management skills can easily lead students off track and create a circle of negative academic emotions when they fail to meet new and unfamiliar demands (Author 1 et al., 2020). The students in this study described how the workshops helped them ease the emotional load by sharing their experiences and hearing that other students experience the same kind of turbulence during their first semester in HE. Students also perceived that they became more aware of their learning processes, which in turn support their transition to HE. 
The expectations and assessment criteria are not always clearly spelled out in HE. It can also be difficult for students to know how they are supposed to reach the learning outcomes. This contributes to insecurity among students, which again can decrease their motivation (Zimmerman, 2000). When students are unsure of what is expected of them and how they should learn they might engage in dysfunctional study strategies (Klassen et al., 2008). Moreover, there are implicit expectations among university teachers that students have adequate time-management skills and are self-disciplined (Mah and Ifenthaler, 2017). If teachers expect students to be able to manage their time and to be self-disciplined, they might not be aware of the need to provide first-year students with support and short-term goals. However, the results of this study show that students need time to acclimatize with a new learning environment as well as to the expectation of taking responsibility for their studying and life as a whole. Procrastination was discussed by most of the students, again indicating how common it is in academia (e.g., Lindblom-Ylänne et al., 2015). Enhancing students' time-management skills as well as students' perceptions of the usefulness of time-management are effective for reducing procrastination (Wolters et al., 2017) which was also shown in our study. However, as this study shows, the reasons for procrastination varied which should be acknowledged when planning interventions.

Moreover, in contrast to the results of Dörrenbächer and Perels (2016), students in this study seemed to benefit from the workshops even if they perceived that they already had good SRL skills or lacked motivation. Rather, as Wingate (2007) suggests, holistic interventions that target all students, like the one described in this study, should be implemented in HE. It is unlikely that students actively seek out these kinds of workshops if they are voluntary. Students already struggling to find time for assignments and courses would likely opt out of voluntary workshops. Thus, this study contributes to the understanding of the challenges and solutions during the first year in HE by allowing students' own interpretations to emerge, which is also recommended by Hailikari et al. (2016). Furthermore, these results need to be implemented in university pedagogy education.

\section{Limitations and suggestions for further research}

The main limitation of this study is that it remains unclear whether these changes in students' awareness of study strategies and SRL processes resulted in actual change in long-term behavior, since no follow-up study was conducted. Moreover, the data were self-reported, which may imply risks such as social desirability or self-serving biases. Nevertheless, the reflective journals were not written for research purposes, and therefore it was unlikely that the students tried to affect the overall results of the research. In addition, the students' journals were only graded pass/fail/needs to be revised and the workshop teachers were not assessing students in their other courses, which might have made it easier for them to be open about their shortcomings and challenges. Due to these limitations longitudinal research is needed to establish the effects of interventions on firstyear university students. Data on academic progression and academic achievements in combination with self-reported data could reduce the risks of social desirability or self-serving bias. Moreover, it would be fruitful to compare how students from different departments perceive interventions that support their transition to $\mathrm{HE}$, since the syllabi vary between departments.

\section{Conclusion}

This study shows that small measures at the beginning of students' university studying can have a major perceived impact on all students' transition to HE. Supporting students' study strategies 
through interventions should be offered to first year students in HE. By providing students with support in their transition to $\mathrm{HE}$, it becomes easier and their progress to more demanding courses is enhanced. Students in this study described how they gained control of their studying by small changes in planning and scheduling and thereby they felt that their overall wellbeing was improved, mostly due to reduced stress. However, only when students become aware of their study strategies, can they reflect on or change them, if needed. The reflective journals proved to be an effective tool for self-reflection and self-evaluation as well as an informative source of knowledge about first-year students' challenges. However, merely being aware of study strategies is not enough. Rather students should be offered opportunities in a safe environment in which their achievements are not assessed to try new strategies in action and thereby strengthen their SRL skills and study confidence. This was explicitly provided during the workshops described in this study by the reflective assignments and discussions. The time-tracking assignment was especially perceived as an eyeopener whereby students realized that they needed to make permanent changes to their study habits in order to succeed academically. Moreover, interventions, such as the workshop in this study, can enhance both academic self-efficacy and performance since they interact reciprocally. They provide a safe environment for students to discuss challenges and solutions. However, these workshops do not offer simple solutions that fit all students. Rather, they provide tools and strategies for the adjustment to HE by enhancing students' metacognitive awareness and SRL skills needed in $\mathrm{HE}$ through personal reflections in relation to their own studying.

\section{Funding}

This study was supported by The Society of Swedish Literature in Finland (SLS).

\section{References}

Al-Sheeb, B. A., Abdulwahed, M. S., \& Hamouda, A. M. (2018), "Impact of first-year seminar on student engagement, awareness, and general attitudes toward higher education", Journal of Applied Research in Higher Education, Vol. 10 No. 1, pp. 15-30.

Asikainen, H., Parpala, A., Lindblom-Ylänne, S., Vanthournout, G., \& Coertjens, L. (2014), “The development of approaches to learning and perceptions of the teaching-learning environment during Bachelor level studies and their relation to study success", Higher Education Studies, Vol. 4 Nr. 4, pp. 24-36.

Broda, M., Yun, J., Schneider, B., Yeager, D. S., Walton, G. M., \& Diemer, M. (2018), "Reducing inequality in academic success for incoming college students: A randomized trial of growth mindset and belonging interventions", Journal of Research on Educational Effectiveness, Vol. 11 No. 3, pp. 317-338.

Brooman, S., \& Darwent, S. (2012a), "A positive view of first-year undergraduate reflective diaries: focusing on what students can do", Reflective Practice, Vol. 13 No. 4, pp 517-531.

Brooman, S., \& Darwent, S. (2012b), "'Yes, as the articles suggest, I have considered dropping out': self-awareness literature and the first-year student", Studies in Higher Education, Vol. 37 No. 1, pp. 19-31.

Cambridge-Williams, T., Winsler, A., Kitsantas, A., \& Bernard, E. (2013), “University 100 orientation courses and living-learning communities boost academic retention and graduation via enhanced self- 
efficacy and self-regulated learning", Journal of College Student Retention: Research, Theory \& Practice, Vol 15 No. 2, pp. 243-268.

Cassidy, S. (2011), "Self-regulated learning in higher education: Identifying key component processes", Studies in Higher Education, Vol. 36 No. 8, pp. 989-1000.

Cho, J. Y., \& Lee, E. H. (2014), "Reducing confusion about grounded theory and qualitative content analysis: Similarities and differences", The Qualitative Report, Vol. 19 No. 32, pp. 1-20.

Cisero, C. A. (2006), "Does reflective journal writing improve course performance?", College Teaching, Vol. 54 No. 2, pp. 231-236.

Dweck, C. S., \& Master, A. (2008), "Self-theories motivate self-regulated learning", in D. H. Schunk, \& B. J. Zimmerman, Motivation and self-regulated learning: Theory, research, and applications, Routledge, New York, pp. 31-51.

Dörrenbächer, L., \& Perels, F. (2016), “Self-regulated learning profiles in college students: Their relationship to achievement, personality, and the effectiveness of an intervention to foster selfregulated learning", Learning and Individual Differences, Vol. 51, pp. 229-241.

Finfgeld-Connett, D. (2014), "Use of content analysis to conduct knowledge-building and theorygenerating qualitative systematic reviews", Qualitative Research, Vol. 14 No. 3, pp. 341-352.

Finnish Advisory Board on Research Integrity. (2012), Responsible conduct of research and procedures for handling allegations of misconduct in Finland. Retrieved from: http://www.tenk.fi/en/responsibleconduct-of-research.

Foerst, N. M., Klug, J., Jöstl, G., Spiel, C., \& Schober, B. (2017), "Knowledge vs. action: Discrepancies in university students' knowledge about and self-reported use of self-regulated learning strategies", Frontiers in Psychology, Vol. 8, pp. 1-12.

Graneheim, U. H., Lindgren, B. M., \& Lundman, B. (2017), “Methodological challenges in qualitative content analysis: A discussion paper", Nurse Education Today, Vol. 56, pp. 29-34.

Haarala-Muhonen, A., Ruohoniemi, M., Parpala, A., Komulainen, E., \& Lindblom-Ylänne, S. (2017), "How do the different study profiles of first-year students predict their study success, study progress and the completion of degrees?", Higher Education, Vol. 74 No. 6, pp. 949-962.

Hailikari, T. K., \& Parpala, A. (2014), "What impedes or enhances my studying? The interrelation between approaches to learning, factors influencing study progress and earned credits", Teaching in Higher Education, Vol. 19 No. 7, pp. 812-824.

Hailikari, T., Sund, R., Haarala-Muhonen, A., \& Lindblom-Ylänne, S. (2019), “Using individual study profiles of first-year students in two different disciplines to predict graduation time", Studies in Higher Education, pp. 1-15.

Hailikari, T., Tuononen, T., \& Parpala, A. (2018), "Students' experiences of the factors affecting their study progress: Differences in study profiles", Journal of Further and Higher Education, Vol. 42 No. 1, pp. 1-12.

Jairam, D. (2020), "First-year seminar focused on study skills: an ill-suited attempt to improve student retention", Journal of Further and Higher Education, Vol. 44 No. 4, pp. 1-15. 
Katz, I., Eilot, K., \& Nevo, N. (2014), "'I'll do it later': Type of motivation, self-efficacy and homework procrastination", Motivation and Emotion, Vol. 38 No. 1, pp. 111-119.

Kim, A. K. (2013), "Reflective journal assessment: The application of good feedback practice to facilitating self-directed learning", Journal of Hospitality, Leisure, Sport \& Tourism Education, Vol. 13, pp. 255-259.

Kim, K. R., \& Seo, E. H. (2015), "The relationship between procrastination and academic performance: A meta-analysis", Personality and Individual Differences, Vol. 82, pp. 26-33.

Klassen, R. M., Krawchuk, L. L., \& Rajani, S. (2008), "Academic procrastination of undergraduates: Low self-efficacy to self-regulate predicts higher levels of procrastination", Contemporary Educational Psychology, Vol. 33 No. 4, pp. 915-931.

Klingsieck, K. B. (2013), "Procrastination: When good things don't come to those who wait", European Psychologist, Vol. 18 No. 1, pp. 24-34.

Leese, M. (2010), "Bridging the gap: Supporting student transitions into higher education", Journal of Further and Higher Education, Vol. 34 No. 2, pp. 239-251.

Lindblom-Ylänne, S. A., Saariaho-Räsänen, E. J., Inkinen, M. S., Haarala-Muhonen, A. E., \& Hailikari, T. K. (2015), "Academic procrastinators, strategic delayers and something betwixt and between: An interview study", Frontline Learning Research, Vol. 3 No. 2, pp. 47-62.

Mah, D. K., \& Ifenthaler, D. (2017), "Academic staff perspectives on first-year students' academic competencies", Journal of Applied Research in Higher Education, Vol 9 No. 4, pp. 630-640.

Official Statistics of Finland OSF (2020), Progress of studies [e-publication]. Helsinki: Statistics Finland, Retrieved from: http://www.stat.fi/til/opku/2019/opku 2019 2020-03-

12 tie 001 en.html.

Perander, K., Londen, M., Holm, G., and Tiihonen, S. (2020), "Becoming a university student: An emotional rollercoaster", Högre Utbildning, Vol. 10 No. 1, pp. 1-12.

Pintrich, P. R. (2004), "A conceptual framework for assessing motivation and self-regulated learning in college students", Educational Psychology Review, Vol. 16 No. 4, pp. 385-407.

Richardson, M., Abraham, C., \& Bond, R. (2012), "Psychological correlates of university students' academic performance: A systematic review and meta-analysis", Psychological Bulletin, Vol. 138 No. 2, pp. 353-387.

Ruohoniemi, M., \& Lindblom-Ylänne, S. (2009), "Students' experiences concerning course workload and factors enhancing and impeding their learning-a useful resource for quality enhancement in teaching and curriculum planning", International Journal for Academic Development, Vol. 14 No. 1, pp. 69-81.

Steel, P. (2007), "The nature of procrastination: A meta-analytic and theoretical review of quintessential self-regulatory failure", Psychological Bulletin, Vol. 133 No. 1, pp. 65-94.

Steel, P., \& Klingsieck, K. B. (2016), "Academic procrastination: Psychological antecedents revisited", Australian Psychologist, Vol. 51 No. 1, pp. 36-46.

Trautwein, C., \& Bosse, E. (2017), "The first year in higher education: Critical requirements from the student perspective", Higher Education, Vol. 73 No. 3, pp. 371-387. 
van Eerde, W., \& Klingsieck, K. B. (2018), "Overcoming procrastination? A meta-analysis of intervention studies", Educational Research Review, Vol. 25, pp. 73-85.

van Rooij, E. C., Jansen, E. P., \& van de Grift, W. J. (2018), “First-year university students' academic success: the importance of academic adjustment", European Journal of Psychology of Education, Vol. 33 No. 4, pp. 749-767.

Wingate, U. (2007), "A framework for transition: Supporting 'learning to learn' in higher education", Higher Education Quarterly, Vol. 61 No. 3, pp. 391-405.

Wolters, C. A., Won, S., \& Hussain, M. (2017), "Examining the relations of time management and procrastination within a model of self-regulated learning", Metacognition and Learning, Vol. 12 No. 3, pp. 381-399.

Yan, V. X., Thai, K. P., \& Bjork, R. A. (2014), "Habits and beliefs that guide self-regulated learning: Do they vary with mindset?", Journal of Applied Research in Memory and Cognition, Vol. 3 No. 3, pp. $140-152$.

Zimmerman, B. J. (1986), "Becoming a self-regulated learner: Which are the key subprocesses?", Contemporary Educational Psychology, Vol. 11 No. 4, pp. 307-313.

Zimmerman, B. J. (2000), "Self-efficacy: An essential motive to learn", Contemporary Educational Psychology, Vol. 25 No. 1, pp. 82-91.

Zimmerman, B. J. (2002), "Becoming a self-regulated learner: An overview", Theory into Practice, Vol. 42 No. 2, pp. 64-70. 